\title{
Barriers to the implementation of Pharmaceutical Care into the UAE community pharmacies
}

\author{
Rana Mohammed Ghazal ${ }^{1}$, Prof. Nageeb Abdul Galil Hassan ${ }^{2}$, Dr. Ola Ghaleb \\ $\mathrm{Al} \mathrm{Ahdab}{ }^{3}$, Ismat Isam Saliem ${ }^{4}$ \\ ${ }^{I}$ (Lecturer, Clinical Pharmacy and Pharmacy Practice Department, Pharmacy College, Ajman University of \\ Science and Technology Network, Ajman, United Arab Emirates.) \\ ${ }^{2}$ (Head of Pharmacology \& Toxicology Department in Ajman University) \\ ${ }_{3}^{3}$ (Pharmaceutical Advisors, Registration and Drug Control Dept. Ministry of Health, UAE.) \\ ${ }^{4}$ (principle trainer in job developments, Dubai Health Authourity)
}

\begin{abstract}
Community pharmacy practice setting provides the opportunity for pharmacists to be "the most accessible health care providers", however still the role of the pharmacists considered as product oriented and mainly concentrate on distribution and prescription filling. In order for advanced pharmacy practice to become an effective reality we must be willing to admit certain challenges embodied by barriers to pharmaceutical care. Thus, this study considered as the first of its kind to be held in UAE community pharmacies aimed to explore the extent of obstacles to the professional services provided through community pharmacies in the UAE and to provide baseline data critical to inform the development of strategies to success implementation of pharmaceutical care. Descriptive Qualitative Survey was conducted, which involved exploring data from randomly selected pharmacists working in different UAE community pharmacies. The respondents asked to indicate the degree of the agreement to (37) barriers to the application of pharmaceutical care, using 5-point Likert-type scale. SPSS software program for windows Version (20) used to perform statistical analysis needed. Frequencies, percentages, means and standard deviations were used to describe pharmacists' responses. MannWhitney U Test and Kruskal-Wallis Test were used to assess the association between these barriers and demographic characteristics. Overall results showed that; lack of time (64.7\%), insufficient staff number (61.9\%) and lack of motivation (61.1\%) are the main barriers to provide pharmaceutical care by community pharmacists in the UAE. The provision of pharmaceutical care is not regarded as such over the seven emirates. Although same barriers can be identified, their local importance showed some differences. There were significant differences in gender, age and experience in the estimate of barriers. Pharmacists expressed a willingness to implement pharmaceutical care practice but have recognized a number of barriers to successful implementation.
\end{abstract}

KEYWORDS - Advance Pharmacy service, Community Pharmacy, Implementation Barriers Pharmaceutical Car, Practice Change

\section{INTRODUCTION}

Over the past few decades gradual and remarkable growth of pharmacy practice and the managed care system have been noticed; pharmacists are employing innovative patient care strategies such as The Pharmaceutical Care Practice (PCP). This practice attracted worldwide attention and its philosophy became the primary mission of pharmacy. Pharmaceutical Care Practice (PCP) mandates the practitioners not only to dispense medications, but also to assume responsibility for improving the quality of patients' outcomes [1].

Under this "Pharmaceutical Care" model, pharmacists make a therapeutic decision in the patient's best medical interests for the purpose of achieving definite results that improve a patient's quality of life (QoL) $[2,3]$.

To achieve these results, pharmacists need to co-operate with patients and other healthcare providers in designing, implementing, and monitoring a care plan aimed at preventing and resolving drug therapy problems (DTPs) [4,5]. For the pharmaceutical care to achieve its goals the perception and understanding towards pharmacy need to be changed and evolved [6,7]. As the pharmacists are the main drive and main factor behind transformation and application of pharmaceutical care practices pharmacists need to reorient practicing to meet the challenges of the contemporary health care system [8,9]. In fact many pharmacists are not routinely engaging in pharmaceutical care activities because of the variety of obstacles they face in community pharmacy settings [10]. Hence, pharmacists' knowledge and perception about the new emerging philosophy of pharmaceutical care and its challenges are at vital concern. 


\section{Overview on community pharmacy practice in UAE}

Pharmacy practice is mainly focused on distribution traditional activities. Pharmacist patient counselling is usually limited to the dosage and frequency of the medications they purchase. Occasionally and on patients' request pharmacists' advise patients about adverse reactions and drug interactions with other medications. Patients' medication reviews and therapy management rarely occurs in private pharmacies [11]

A study conducted in 2011 in UAE community pharmacies to explore positive outcomes to active pharmacists counseling, revealed that pharmacists recognized that effective counseling will increase their sales and enhance their pharmacies reputation [12]. However, another study conducted in 2012 showed that enhanced professional services were not provided to a large extent in most pharmacies [13]. The later study also revealed that; less than one third of the pharmacist counselled patients on a regular basis, a quarter of pharmacists claimed that they reported medication errors and adverse drug reactions, most pharmacies (92\%) did not routinely keep patient records. However, these activities were not often performed in around $40 \%$ of the pharmacies. In conclusion community pharmacists play a key role in helping people manage conditions that are largely controllable through drug therapy and in reducing health care costs. Yet, many are not routinely engaging in pharmaceutical care activities because of variety of obstacles. Thus, present study aimed to highlight barriers of pharmaceutical care implementation in community pharmacies in the UAE, and assess their extent in creating gap between theoretical and applied care practice.

\section{MATERIAL AND METHODS}

In order to get an overview of the barriers perceived by UAE community pharmacists for implementing pharmaceutical care, descriptive qualitative survey was carried out over the seven emirates of the UAE community pharmacies which involved exploring and collecting data from randomly selected pharmacists.

The initial pool of barriers items were identified by previous studies [14-20]. Modifications were done to make it convenient with the UAE practice setting. The questionnaire compromised of 3 parts: section one contained questions related to the demographic characteristics and other practice shapes in community pharmacy settings, section two explored the respondent's perception with regards to the barriers on the provision of pharmaceutical care practice and the final part was open-ended part in which the respondents provided suggestions to overcome such barriers.

By the use of Raosoft sample size calculator the minimum sample size was calculated to be 270 and the final chosen sample size was 500 to overcome non response and to avoid decreased sample size than minimum.

Content Validity of the Study The survey tool was reviewed by doctors and lecturers of pharmacy department at Ajman University of Science \& Technology (AUST) to establish content validity of the questionnaire. The purpose was to assess general acceptance of the survey instrument, comprehension, questions organization and sequencing. Based on the feedback, the survey questions were adjusted before primary distribution to the participants.

In a small scale preliminary pilot study the questionnaire was distributed in Dubai International pharmaceuticals and technologies conference and exhibition (Duphat) in 2013. It was self-administered to random sample of pharmacists working in the UAE. The comments and the results were reviewed and discussed with research's supervisors for further comments and suggestions. The questionnaire was looked out for misunderstandings in terms of wordings, sentence constructions and ambiguity and at that point proper modification was done to the questionnaire. After minor modifications in some questions words and language, the questionnaire was well structured to its final format.

The reliability test for questionnaire items were measured by using Cronbach's Alpha coefficient and reported to be 0.95 (Values above 0.7 are acceptable, and those above 0.8 are preferable).

Data Analysis: All questions were coded and then they were imported for Statistical Package for the Social Sciences (SPSS) Version (20) for windows in order to perform proper analysis. Descriptive statistics were used to analyze direct questions and demographic data obtained from the research (i.e. frequency distribution, percentile, mean, and standard deviation). Mann Whitney Test and Kruskal-Wallis Test were used to measure possible association between demographic data and barriers. 


\section{RESULTS}

A total of 500 questionnaires were distributed during a period from April to August 2013. Of these, 357 were completed and retained (response rate $71.4 \%$ ).

The respondents were primarily males (63.3\%) and most were aged 32.13 years with Standard Deviation (SD) of 7.325. Most participants are B-pharm qualification (91.9\%) and about (66.6\%) did not join professional development courses. Participants have work experience on average of 7.16 years with Standard Deviation (SD) of 5.595. Most participants worked in Groups of pharmacies (54.6\%) owned by pharmacists $(65.5 \%)$, and nearly they are serving more than $50 \%$ patients per day $(54.9 \%)$. About $92.9 \%$ of the pharmacists keep references to retain to in their pharmacies. Most of community pharmacies were in Abu-Dhabi and Dubai, the size and the percentage was $(n=357 ; 56.9 \%)$.

Main Barriers that Challenging Pharmaceutical Care Implementation into the UAE Community Pharmacies:

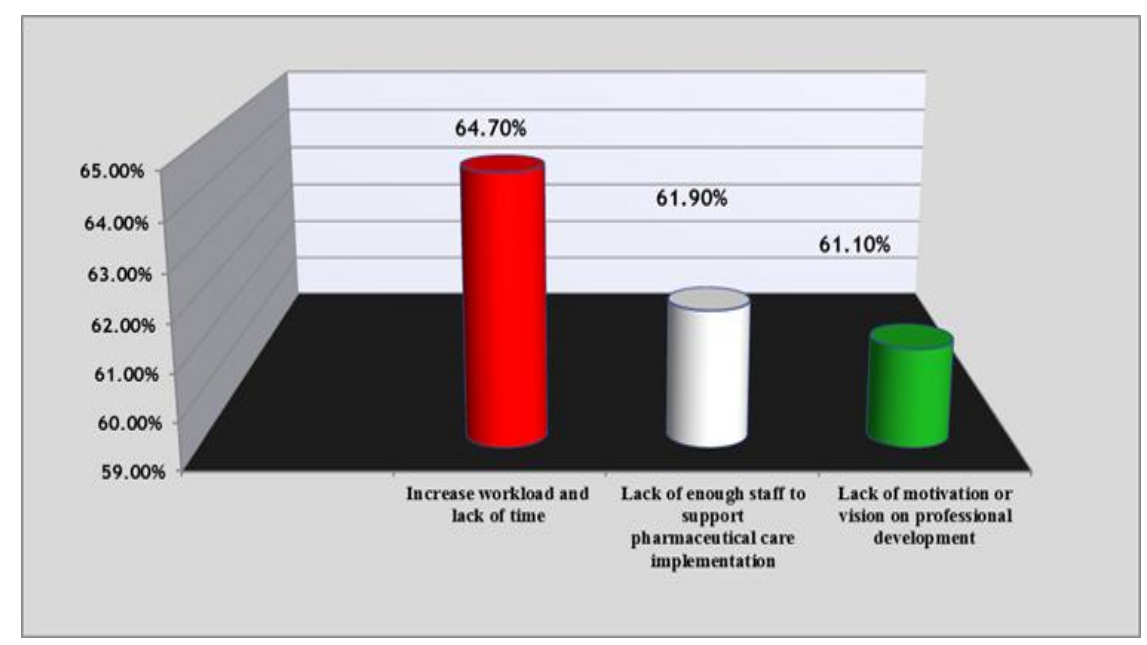

Figure \{1\}: Highest Barriers to Pharmaceutical Care Implementation in the UAE

Main Barriers that Challenging Pharmaceutical Care Implementation in each emirate of the UAE

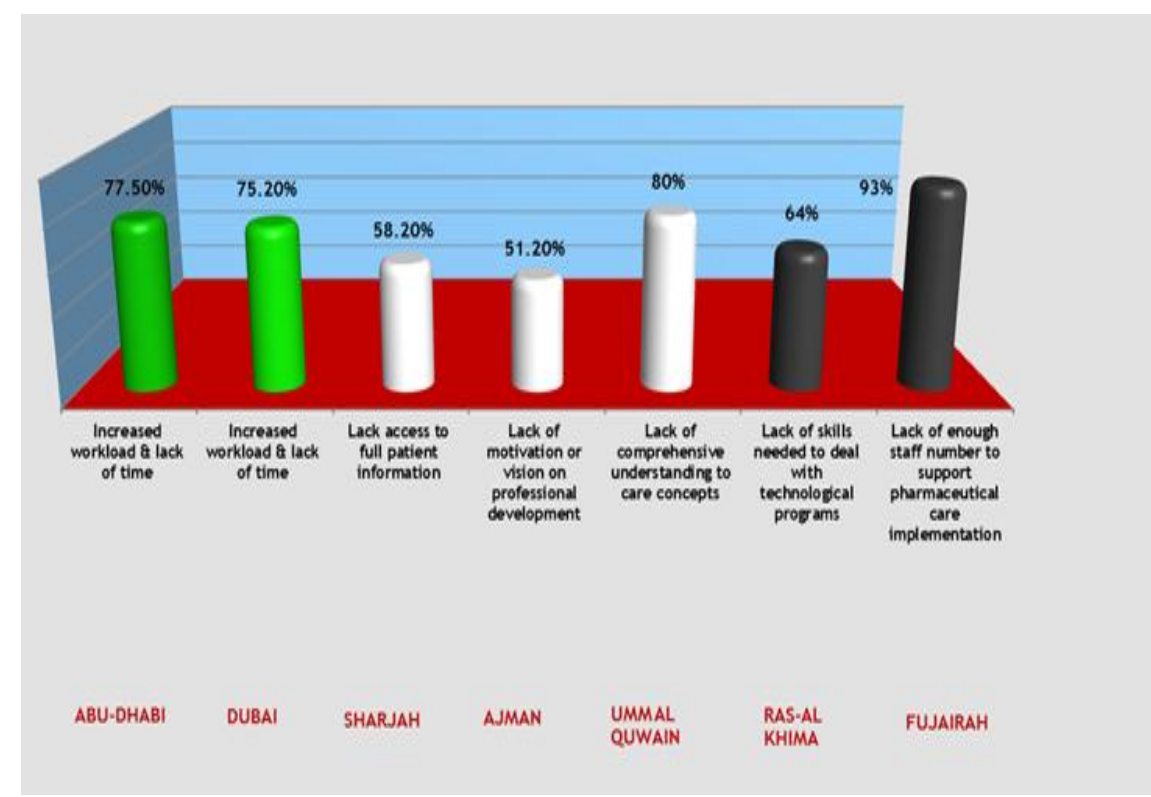

Figure \{2\}: Highest Barriers to Pharmaceutical Care Implementation in each emirates of the UAE 
Table (1): Proportion of pharmacists' views regarding barriers to provide Pharmaceutical care in The United Arab Emirates

\begin{tabular}{|c|c|c|c|}
\hline Statements of barriers to pharmaceutical care & $\%$ of parti & Jants view res & \\
\hline & Dis-Agree & No Opinion & Agree \\
\hline Lack of comprehensive understanding to care concepts & $26.10 \%$ & $14.30 \%$ & $59.70 \%$ \\
\hline Misconception between providing care $\&$ routine cancelling & $24.40 \%$ & $21.00 \%$ & $54.60 \%$ \\
\hline Fear of change to new profession & $29.40 \%$ & $20.20 \%$ & $50.40 \%$ \\
\hline Lack of motivation or vision on professional development & $24.10 \%$ & $18.00 \%$ & $61.10 \%$ \\
\hline Product oriented practice & $30.30 \%$ & $24.90 \%$ & $44.80 \%$ \\
\hline Less involvement in Health Projects & $30.80 \%$ & $20.70 \%$ & $48.50 \%$ \\
\hline Lack of therapeutic knowledge for adequate counseling & $31.10 \%$ & $18.20 \%$ & $50.70 \%$ \\
\hline Lack access to effective Drug information resources & $30.80 \%$ & $23.00 \%$ & $46.20 \%$ \\
\hline Lack systemic approach to clinical problem-solving & $23.00 \%$ & $25.50 \%$ & $51.50 \%$ \\
\hline Lack of counseling guideline or plan for effective patient counseling & $21.30 \%$ & $24.40 \%$ & $54.30 \%$ \\
\hline Lack of documentation to provided care & $23.80 \%$ & $29.70 \%$ & $46.50 \%$ \\
\hline Lack care courses in undergraduate curriculum & $22.70 \%$ & $27.20 \%$ & $50.10 \%$ \\
\hline Lack continuity of quality improvement & $24.90 \%$ & $21.30 \%$ & $53.80 \%$ \\
\hline Lack of education in communication skill & $28.60 \%$ & $14.00 \%$ & $57.40 \%$ \\
\hline Lack of education in skills needed to deal with technology & $31.90 \%$ & $14.60 \%$ & $53.50 \%$ \\
\hline Lack access to full patient information & $20.20 \%$ & $21.80 \%$ & $58.00 \%$ \\
\hline Language barrier & $22.70 \%$ & $17.40 \%$ & $59.90 \%$ \\
\hline Disparity of cultures \& believes & $24.60 \%$ & $31.10 \%$ & $44.30 \%$ \\
\hline Patient literacy & $16.50 \%$ & $34.70 \%$ & $48.70 \%$ \\
\hline Lack of patient interest & $26.90 \%$ & $23.80 \%$ & $49.30 \%$ \\
\hline Socioeconomic status of patients & $20.70 \%$ & $33.10 \%$ & $46.20 \%$ \\
\hline Nature of pharmacy location & $23.80 \%$ & $20.70 \%$ & $55.50 \%$ \\
\hline Space and layout within the pharmacy & $27.50 \%$ & $25.50 \%$ & $47.10 \%$ \\
\hline Inadequate private counseling area & $21.30 \%$ & $21.60 \%$ & $57.10 \%$ \\
\hline Non commitment to professional appearance & $34.50 \%$ & $22.10 \%$ & $43.40 \%$ \\
\hline Lack of time & $16.20 \%$ & $19.00 \%$ & $64.70 \%$ \\
\hline Lack of staff number & $22.10 \%$ & $16.00 \%$ & $61.90 \%$ \\
\hline Lack of trained staff & $25.20 \%$ & $15.70 \%$ & $59.10 \%$ \\
\hline Lack of financial capital & $22.10 \%$ & $27.50 \%$ & $50.40 \%$ \\
\hline Lack of insurance assistance programs & $22.70 \%$ & $31.10 \%$ & $46.20 \%$ \\
\hline Lack of software for medication assessment support & $28.00 \%$ & $27.20 \%$ & $44.80 \%$ \\
\hline Improper utilization of formulary & $20.40 \%$ & $28.90 \%$ & $50.70 \%$ \\
\hline Legislation barriers & $21.30 \%$ & $34.50 \%$ & $44.30 \%$ \\
\hline Non-supportive pharmacy management regulations & $29.70 \%$ & $26.30 \%$ & $44.00 \%$ \\
\hline Other Health Care Professional resistance to interactions & $21.60 \%$ & $30.00 \%$ & $48.50 \%$ \\
\hline Lack of teamwork concept & $26.10 \%$ & $18.80 \%$ & $55.20 \%$ \\
\hline Lack of profession fees to reward care services & $16.00 \%$ & $30.00 \%$ & $54.00 \%$ \\
\hline
\end{tabular}

Assessment of the influence of gender, age and experience on the barriers of pharmaceutical care implementation showed numerous statistically significant findings

Regarding the Gender, Females significantly acknowledged that "less involvement in Health projects" and "Language barrier" were important barriers, than males (P Value $\leq 0.05)$. Concerning the Age, Middle aged pharmacies "30-44 years" were more conscious to most of barriers (P Value $\leq 0.001$ ). Regarding the experience, results showed that highly significant difference between pharmacists with experience between 5 to 10 years and the other groups (P Value $\leq 0.01)$. 


\section{DISCOUSION \& CONCLUSION}

The overall results of the present study showed that:

The main barriers that challenging pharmaceutical care implementation into UAE community pharmacies were lack of time, insufficient staff number and lack of motivation or vision on professional development which represented a percentage of $64.7 \%, 61.9 \%$ and $61.1 \%$ respectively. These findings most probably strongly interrelated; as increased in workload decreases the time needed for advanced patient counselling which is correlated of the increase demand to supportive personnel and therefore, pharmacists are unable to show the professionalism required to get appreciation of catalyst for advanced care.

The results of the present study were compatible with European barriers to the implementation of pharmaceutical care [15] in their findings of lack time and trained staff. Moreover their findings showed that lack of remuneration has great effect in the progression of the practice. Lack of pharmacists' time was also identified in many other studies [15,17,21,22] as the major barrier limiting pharmacists' provision of advance health services. However, other studies findings showed some differences. American and New Zealand studies found that the most common barriers identified for pharmacists providing advance pharmacy services with or without compensation were related to compensation. [23,24]. Recent study in Jordan revealed that pharmaceutical care training was found to be the top barrier to the provision of pharmaceutical care. [25]

The provision of pharmaceutical care is not regarded as such over the seven emirates; although same barriers can be identified but, their local importance showed some differences.

Particular results showed that $77.5 \%$ and75.2\% of pharmacists in Abu Dhabi and Dubai respectively, had reported that insufficient pharmacist patient contact time as strong barrier to advance care practice. This finding reflected that pharmacists there were facing increased workload due to increase number of customers visiting these pharmacies. This is expected in Abu Dhabi as being the capital and in Dubai as being a tourist destination. This may necessitate recruitment of enough trained personnel to counteract the additional barrier faced by the pharmacists in the shortage of supported staff.

In Sharjah $58.20 \%$ of pharmacists acknowledged that lack of access to full patient information as an important barrier to pharmaceutical care implementation. Therefore, lack awareness to such concept may affect pharmacists' professionalism.

In Ajman $51.20 \%$ pharmacists reported lack of motivation or vision on professional development as a robust hinder to the practice. Thus, goal oriented approach may has its effect toward higher productivity and better level of patients' service.

In Umm Al Quwain, 80\% of pharmacists agreed that lack of comprehensive understanding to care concepts as a robust barrier to pharmaceutical care.

In Ras Al Khima, lack of skill needed to deal with technology was reported by $64 \%$ of pharmacists. Therefore, it is important that care programs take advantage of new developments in health information technology.

In Fujairah many barriers were shared with the other emirates. However, $93 \%$ of pharmacists were facing additional number of obstacles. It is likely to say that pharmacists in Fujairah have good understanding to pharmaceutical care concepts but lacking practical solutions to face such obstacles. This was noticed when statement like "lack of comprehensive understanding to care concepts "was less understood by Fujairah pharmacists to be one of the highest reason of delayed pharmaceutical care practice in their pharmacies.

Regarding the influence of gender, age and experience on the barriers of pharmaceutical care implementation results showed numerous finding.

Our finding regarding the gender revealed that no big differences between genders in the awareness to care barriers. This finding matched other study like Al-Arifi et al study [17].

Concerning the age, results showed that there were significant differences between pharmacists who were less than 30 years and those who were $\geq 30$ years on most of the Barriers statements. However, middle aged pharmacies were more conscious to most of barriers. This finding matched Malaysia study [26].

Regarding the experience, results showed that highly significant difference between pharmacists. Pharmacists having experience less than 5 years were less likely to agree with most of the barriers. This finding indicated that pharmacists within this group tended to be less aware to such barriers. And this result was contradicted with Malaysia study [26] as they found that pharmacists with experience less than 5 years were more likely to agree on most barriers. 
V.

CONCLUSION:

Identifying perceived barriers to implementing of pharmaceutical care services and gaining pharmacists' perceptions of these barriers is critical to encouraging the expansion of patient care services in UAE community practices.

Policies and procedures regarding the provision of pharmaceutical care in community pharmacy settings should consider the particular type of setting as well as the characteristics of the population served.

Several demographic factors and practice setting characteristics were associated with awareness of pharmacists toward barriers to pharmaceutical care.

While pharmaceutical care provision is limited at this stage in UAE, considered strategies should be addressed to overcome barriers to successful implementation.

\section{RECOMMENDATIONS:}

Pharmacists will need to be competent and possess both vision and a voice to fully integrate into the health care team. Pharmacists' personality and their professionalism is an important matter.

Pharmacists' attitude is favorable when adequate time is available for the performance of a pharmaceutical care service. So, pharmacists should be freed to a greater extent from performing routine tasks which could be delegated with supervision to trained supportive personnel, thereby expanding professional pharmacy service.

Health care interventions can no longer be based on opinion or individual experience alone. Scientific evidence built up from good quality research must be used as a guide and adapted to each individual patient's circumstances.

Change cannot occur without support from pharmacy regulatory authorities and governments, and their commitment to review and amend policies, regulation or legislation to address and encourage initiatives to pharmaceutical care implementation.

\section{Limitations and restrictions of the study}

Possibility of nonresponse bias, it is unknown whether non-respondents differed from those who responded. The survey was relatively lengthy, which has led to increase difficulty to data collecting procedure. The study did not target assistants' pharmacists. However they may play a part in overall assessing barriers to the practice.

\section{Significance of the study:}

The concept of Pharmaceutical Care has been developed and become central to modern community pharmacy practice. However, its daily practice has been delayed by a number of barriers to implementation. Various studies have discussed such obstacles in general, while little is known about issues and barriers that hinder the delivery of pharmaceutical care in community pharmacies setting.

Thus, this study considered as the first of its kind to be held in UAE community pharmacies, seeking to assess perceived obstacles to pharmaceutical care implementation. A well perception to these barriers will be a base to bridge the gap between theoretical and applied pharmaceutical care. The potential benefits that may result from this study will provide information to the decision makers to have an inclusive picture of the practicality to develop and implement such practice.

\section{Suggestions for future research}

Researches to be conducted to identify strategies to overcome the barriers of implementing pharmaceutical care, As well Researches are needed to evaluate the impact of health care policies on development of pharmacy practice. 


\section{REFERENCES}

[1] Hepler, C. D., \& Strand, L. M. Opportunities and responsibilities in pharmaceutical care. Am J Hosp Pharm, 47(3) 1990, 533-43.

[2] Hoffmann, R. L., Rohrer III, W. M., South-Paul, J. E., Burdett, R., \& Watzlaf, V. J. The effects of barriers on Health Related Quality of Life (HRQL) and compliance in adult asthmatics who are followed in an urban community health care facility. Journal of community health, 33(6) 2008, 374-383.

[3] Johnson, J. A., \& Bootman, J. L. Drug-related morbidity and mortality: a cost-of-illness model. Archives of Internal Medicine, $1995,155(18), 1949$

[4] Bell, J. S., Whitehead, P., Aslani, P., McLachlan, A. J., \& Chen, T. F. Drug-related problems in the community setting. Clinical drug investigation,26(7) 2006, 415-425.

[5] Ax, F., Brånstad, J. O., \& Westerlund, T. Pharmacy counselling models: a means to improve drug use. Journal of clinical pharmacy and therapeutics, 35(4), 2010, 439-451.

[6] Winslade, N. Large group problem-based learning: a revision from traditional to pharmaceutical care-based therapeutics. American Journal of Pharmaceutical Education, 58(1), 1994, 64-72.

[7] Al-Shaqha WM \& Zairi M. "Pharmaceutical care management: a modern approach to providing seamless and integrated health care.", International journal of health care quality assurance incorporating Leadership in health services, vol. 14(7), 2001, 841120

[8] Albanese, N. P., \& Rouse, M. J. Scope of contemporary pharmacy practice: roles, responsibilities, and functions of pharmacists and pharmacy technicians. Journal of the American Pharmacists Association: JAPhA, 50(2), 2010,1030.

[9] Doucette, W. R., Kreling, D. H., Schommer, J. C., Gaither, C. A., Mott, D. A., \& Pedersen, C. A. Evaluation of community phar macy service mix: evidence from the 2004 National Pharmacist Workforce Study. Journal of the American Pharmacists Association, 46(3), 2006,348-355.

[10] Benrimoj, S. I., \& Frommer, M. S. Community pharmacy in Australia.Australian Health Review, 28(2), 2004, $238-246$.

[11] Dameh, Majd. Pharmacy in the United Arab Emirates. Southern med review, 2(1) 2009, 15.

[12] Hamoudi, N. M., Shirwaikar, A. A., Ali, H. S., \& Al Ayoubi, E. I. Pharmaceutical consultation in UAE community pharmacies.Indian journal of pharmaceutical sciences, 73(4) 2011, 404

[13] Hasan, S., Sulieman, H., Chapman, C. B., Stewart, K., \& Kong, D. Community pharmacy services in the United Arab Emirates. International Journal of Pharmacy Practice, 20(4) 2012, 218-225.

[14] Scott, D. M., Narducci, W. A., Jungnickel, P. W., Miller, L. G., Ranno, A. E., \& Maloley, P. A. Pharmaceutical care preceptor training and assessment in community pharmacy clerkship sites. American Journal of Pharmaceutical Education, 63, 1999, $265-271$.

[15] Mil, J. W. F., Boer, W. O., \& Tromp, T. H. European barriers to the implementation of pharmaceutical care. International Journal of Pharmacy Practice, 9(3) 2001, 163-168

[16] Brown, C. M., Barner, J. C., \& Shepard.Issues and barriers related to the provision of pharmaceutical care in community health centers and migrant health centers. J Am Pharm Assoc., 43:75-2003,-7

[17] Al-Arifi, M. N., Al-Dhuwaili, A. A., Gubara, O. A., Al-Omar, H. A., Al-Sultan, M. S., \& Saeed, R. I. Pharmacists' understanding and attitudes towards pharmaceutical care in Saudi Arabia. Saudi Pharmaceutical Journal, 15(2) 2007, 146.

[18] Blake, K. B., \& Madhavan, S. S. Perceived barriers to provision of medication therapy management services (MTMS) and the likelihood of a pharmacist to work in a pharmacy that provides MTMS. The Annals of pharmacotherapy, 44(3) 2010, 424-431.

[19] Jorgenson, D., Lamb, D., \& MacKinnon, N. J. Practice change challenges and priorities: A national survey of practising pharmacists.Canadian Pharmacists Journal/Revue des Pharmaciens du Canada, 144(3) 2011, 125-131.

[20] Uema, S. A., Vega, E. M., Armando, P. D., \& Fontana, D. Barriers to pharmaceutical care in Argentina. Pharmacy World \& Science, 30(3) 2008, 211-215.

[21] Farris, K. B., \& Schopflocher, D. P. Between intention and behavior: an application of community pharmacists' assessment of pharmaceutical care. Social science \& medicine, 49(1) 1999, 55-66.

[22] Gastelurrutia, M. A., Benrimoj, S. C., Castrillon, C. C., de Amezua, M. J. C., Fernandez-Llimos, F., \& Faus, M. J. Facilitators for practice change in Spanish community pharmacy. Pharmacy world \& science, 31(1) 2009, 32

[23] Lounsbery, J. L., Green, C. G., Bennett, M. S., \& Pedersen, C. A. Evaluation of pharmacists' barriers to the implementation of medication therapy management services. Journal of the American Pharmacists Association: JAPhA, 49(1) 2008, 51-58

[24] Dunlop, J. A., \& Shaw, J. P. Community pharmacists' perspectives on pharmaceutical care implementation in New Zealand. Pharmacy World and Science, 24(6) 2002, 224-230.

[25] AbuRuz, S. M., Al-Ghazawi, M. A., Bulatova, N., Jarab, A. S., Alawwa, I. A., \& Al-Saleh, A. Expectations and experiences of physicians regarding pharmaceutical care and the expanding role of pharmacists in Jordan. Jordan Journal of Pharmaceutical Sciences, 5(1) 2012, 2768

[26] Sarriff, A., Gillani, W. S., Babiker, G. A. R. M., \& USM, S. M. Pharmacist Perception to Importance and Self Competence in Pharmacy Practice. IJPSR, 1(2) 2010, 1-21. 